\title{
First record of the rarely collected ant Protanilla gengma Xu, 2012 (Hymenoptera, Formicidae, Leptanillinae) from the Indian subcontinent
}

\author{
Punnath Aswaj, Karunakaran Anoop, Dharma Rajan Priyadarsanan
}

Ashoka Trust for Research in Ecology and the Environment, Royal Enclave, Srirampura, Jakkur Post, Bengaluru - 560064, Karnataka, India. Corresponding author: Dharma Rajan Priyadarsanan, priyan@atree.org

\begin{abstract}
Protanilla gengma $\mathrm{Xu}, 2012$ is recorded for the first time from the Indian subcontinent. This rarely collected ant species was previously known only from Yunnan Province, China. Two workers of P. gengma were collected from the Lengteng Wildlife Sanctuary, Mizoram, Northeast India, using the Winkler extraction method. This find also represents the first record of the subfamily Leptanillinae from Northeast India and the third species of the genus Protanilla Taylor, 1990 from India. We present an updated distribution map for the genus and comment on morphological variation of the worker caste of P. gengma.
\end{abstract}

\section{Keywords}

Eastern Himalayas, Indian ant fauna, Mizoram, Northeast India, Winkler extractor

Academic editor: Gabriela P. Camacho | Received 30 July 2020 | Accepted 11 November 2020 | Published 26 November 2020

Citation: Aswaj P, Anoop K, Priyadarsanan DR (2020) First record of the rarely collected ant Protanilla gengma Xu, 2012 (Hymenoptera, Formicidae, Leptanillinae) from the Indian subcontinent. Check List 16 (6): 1621-1625. https://doi.org/10.15560/16.6.1621

\section{Introduction}

Leptanillinae is a subfamily of rarely collected subterranean ants and is arguably one of the earliest branching lineages of extant ants (Ward 2014; Man et al. 2017). Together with Martialinae, they form the leptanilloid clade, which is sister group to all other ants (Borowiec et al. 2019). Leptanillines are small ants which are infrequently collected and hence very little is known about their habitats and behavior. Based on collection records, the subfamily is distributed in tropical and warm temperate regions of the Old World and Australian regions (Baroni-Urbani 1977; Bolton 1990). To date, eight extant genera have been described in the Leptanillinae (AntCat 2020).

Belonging to this subfamily is the genus Protanilla Taylor, 1990, which was originally described by Bolton
(1990), with the Southeast Asian Protanilla rafflesi Taylor, 1990 as its type species. Since then, the genus has been reported from the southern Palearctic, Oriental, and Indo-Australian regions (Fig. 1; Baroni-Urbani and De Andrade 2006; Man et al. 2017). Currently, the genus encompasses 13 valid species: $P$. rafflesi; $P$. bicolor Xu, 2002; P. concolor Xu, 2002; P. furcomandibula Xu \& Zhang, 2002; P. schoedli Baroni-Urbani \& De Andrade, 2006; P. lini Terayama, 2009; P. tibeta $\mathrm{Xu}, 2012$; P. gengma Xu, 2012; P. izanagi Terayama, 2013; P. wardi Bharti \& Akbar, 2015; P. jongi Hsu, P.W., Hsu, F. C., Hsiao \& Lin, 2017, P. beijingensis Man, Ran, Chen \& Xu, 2017; and P. flamma Baidya \& Bagchi 2020 (AntWiki 2020). 

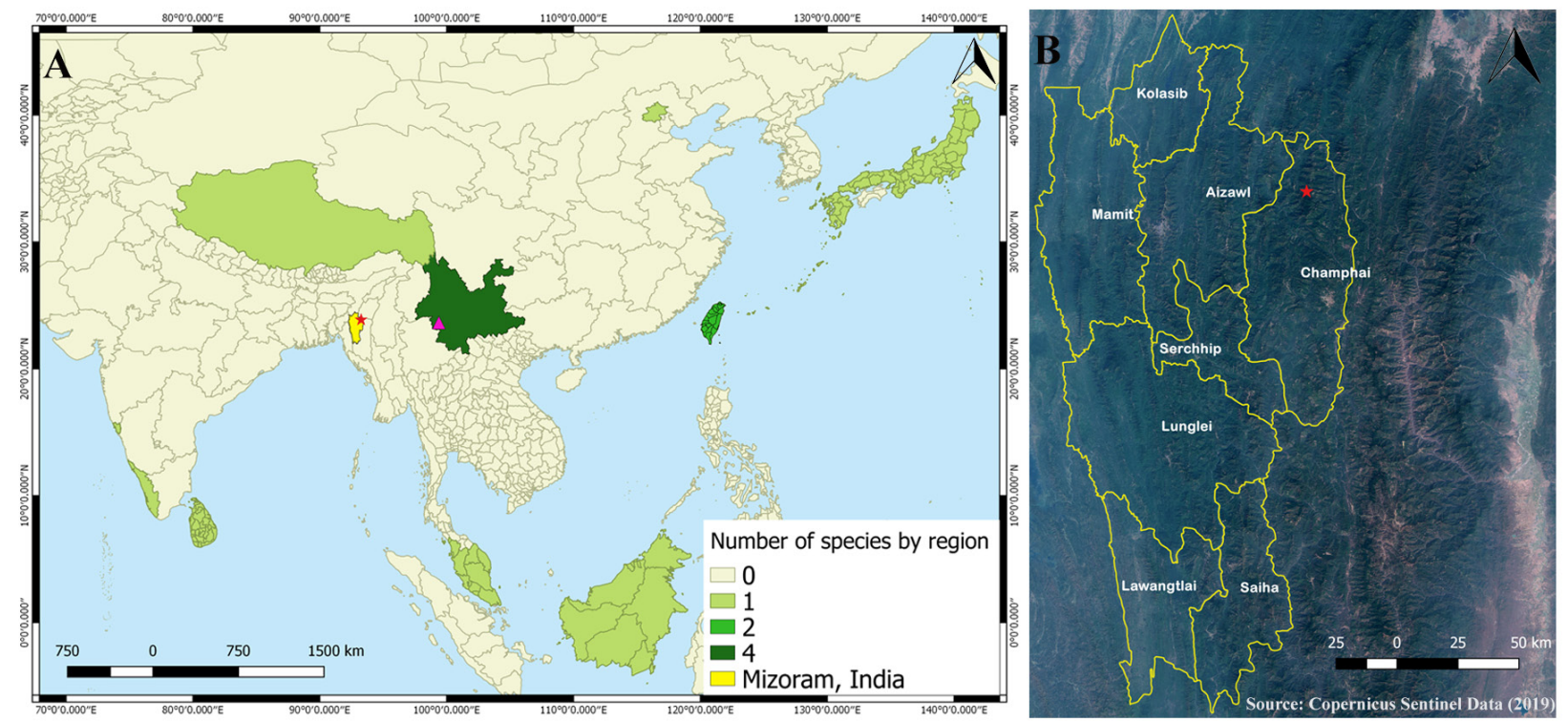

Figure 1. A. Distribution map of Protanilla. Pink triangle icon: previously known records of Protanilla gengma from Yunnan Province, China; red star: new record of $P$. gengma from Mizoram state, India. B. Satellite image (Source: Copernicus Sentinel data, 2019) of the study region, with district boundaries of the state of Mizoram marked in yellow. The red star depicts the location within the Lengteng Wildlife Sanctuary, from where $P$. gengma was collected.

In the Indian subcontinent, Protanilla has been recorded only from India and Sri Lanka. The discovery of $P$. wardi from Silent Valley, Kerala and P. flamma from Netravali Wildlife Sanctuary, Goa are the only reports of this genus from India until now (Bharti and Akbar 2015; Baidya and Bagchi 2020), while P. schoedli was described based on a single queen from Sri Lanka (Baroni-Urbani and De Andrade 2006). The worker caste of P. schoedli was described later from Sri Lanka based on the type locality and overall similarity in morphological features with the holotype queen (Dias et al. 2019).

We present the first record of $P$. gengma from the Indian subcontinent, which also represents the first record of Leptanillinae from the Northeast India, encompassing the Himalaya and Indo-Burma biodiversity hotspots. Protanilla gengma is a rarely collected ant species which was previously known only from the Yunnan Province, China, in the Oriental region (Xu 2012; Man et al. 2017). The original description of the species is based on the worker caste and was collected from a soil sample in monsoon evergreen broadleaf forest at an altitude of $1760 \mathrm{~m}$ (Xu 2012). Our record of P. gengma from the Indian subcontinent is an important contribution to the knowledge of the ant fauna in the Eastern Himalayas.

\section{Methods}

We collected two specimens belonging to the genus Protanilla in the Lengteng Wildlife Sanctuary, Champhai district of Mizoram, Northeast India, at an elevation of 1615 m a.s.l., in April 2019. The collection site was a shaded spot with about $70 \%$ canopy cover within a tropical wet evergreen forest. There were no indications of anthropogenic disturbances. The specimens were collected using a Winkler extractor from sifted leaf litter of
$1 \mathrm{~m}^{2}$, which accounted for $750 \mathrm{ml}$ of leaf litter and rendered the collection of two additional ant genera, Tetramorium Mayr, 1855 and Pheidole Westwood, 1839.

Protanilla specimens were examined under a Zeiss SteREO Discover.V8 microscope. Specimens were imaged at 200× magnification and extended focus montage images were taken using a Keyence VHX 6000 digital microscope. Images were processed into figures using Adobe Photoshop CC 2019. Standard measurements and indices presented here were adapted from Bolton (1987) and Xu (2012). All the body measurements were taken using Keyence VHX 6000 software and verified using a Leica microscope with an attached optical micrometer. The species was identified with the aid of a taxonomic key provided by Baidya and Bagchi (2020) and by comparisons with original descriptions and type images of related species such as $P$. gengma and $P$. bicolor. The images of the holotype of $P$. gengma were obtained from Dr Zhenghui Xu (Faculty of Conservation Biology, Southwest Forestry College, Yunnan Province, China), while the images of a paratype of P. bicolor were accessed on AntWeb.org (2020, CASENT0235341, photos by Michele Esposito, California Academy of Sciences, San Francisco, USA). The distribution of Protanilla species was assessed using AntMaps.org (Janicki et al. 2016; Guénard et al. 2017) and a modified distribution map was prepared using QGIS v. 3.10.4 (QGIS 2020). The specimens are deposited in the ant collection of ATREE Insect Museum, Bangalore, India (AIMB).

Data resources. The data underpinning the analysis reported in this paper are deposited at GBIF, the Global Biodiversity Information Facility, and are available at https://doi.org/10.15468/8mut7m (Aswaj et al. 2020). 


\section{Results}

\section{Protanilla gengma $\mathrm{Xu}, 2012$}

Figure 2

New records. INDIA - 2 workers; Mizoram, Champhai district, Lengteng Wildlife Sanctuary; $23.8678^{\circ} \mathrm{N}$, 093.2598 E; 1615 m a.s.l.; 12 Apr. 2019; Aswaj Punnath \& Anoop Karunakaran leg.; Winkler extraction method; AIMB/Hy/Fr 25001, AIMB/Hy/Fr 25002.

Identification. Measurements (in $\mathrm{mm}$ ): total length 4.15, 4.16; head length $0.69,0.66$; head width $0.60,0.58$; cephalic index 87,88 ; scape length $0.64,0.63$; scape index 107, 109; mandibular length $0.42,0.41$; pronotal width $0.49,0.47$; alitrunk length $1.15,1.13$; petiolar node length $0.37,0.37$; petiolar node height $0.48,0.48$; petiolar node width $0.28,0.27$; postpetiolar node length $0.36,0.37$; postpetiolar node height $0.51,0.52$; postpetiolar node width $0.30,0.31(n=2)$.

The general appearance of $P$. gengma is similar to the Chinese $P$. bicolor in the following: mandibles thin, long and narrowly triangular, without a dorsal lamella; lateral and ventral margin of mandibles smooth, without denticles; postpetiole narrowly attached to abdominal segment IV; in dorsal view, petiole distinctly longer than broad, laterally compressed and roughly elliptic; body bicolored, middle portion black, remainder of body brownish yellow or blackish brown. However, it differs from $P$. bicolor in the following characters: in full face view, anterior half of head distinctly narrowed (anterior one-third of the head distinctly narrowed in P. bicolor); in profile view, petiolar node evenly rounded, with no differentiation of anterior and dorsal faces (anterior and dorsal faces of petiolar node somewhat differentiated, meeting at a broadly rounded angle in $P$. bicolor); body large, head width $0.58-0.65 \mathrm{~mm}$ (body small, head width $0.42-0.45 \mathrm{~mm}$ in $P$. bicolor); head light black to blackish brown (head brownish yellow in $P$. bicolor).

Our specimens of $P$. gengma from India vary morphologically from specimens from Yunnan, China (Fig. 3 ). The Indian specimens in full face view have a medially concave posterior clypeal margin; the mandibular insertion to head clearly visible and not concealed by the clypeus; the anterolateral margin of clypeus weakly arched in front of antennal socket; and the apex of labrum with three peg-like setae. The Yunnan specimens have a strongly convex posterior clypeal margin; the mandibular insertion not distinctly visible but concealed by the clypeus in full face view; the anterolateral corner of clypeus strongly arched in front of antennal socket; and the apex of labrum with four peg-like setae. Despite the above differences, we were able to confirm the species identity based on the overall similarity in diagnostic characters, images, and body measurements.
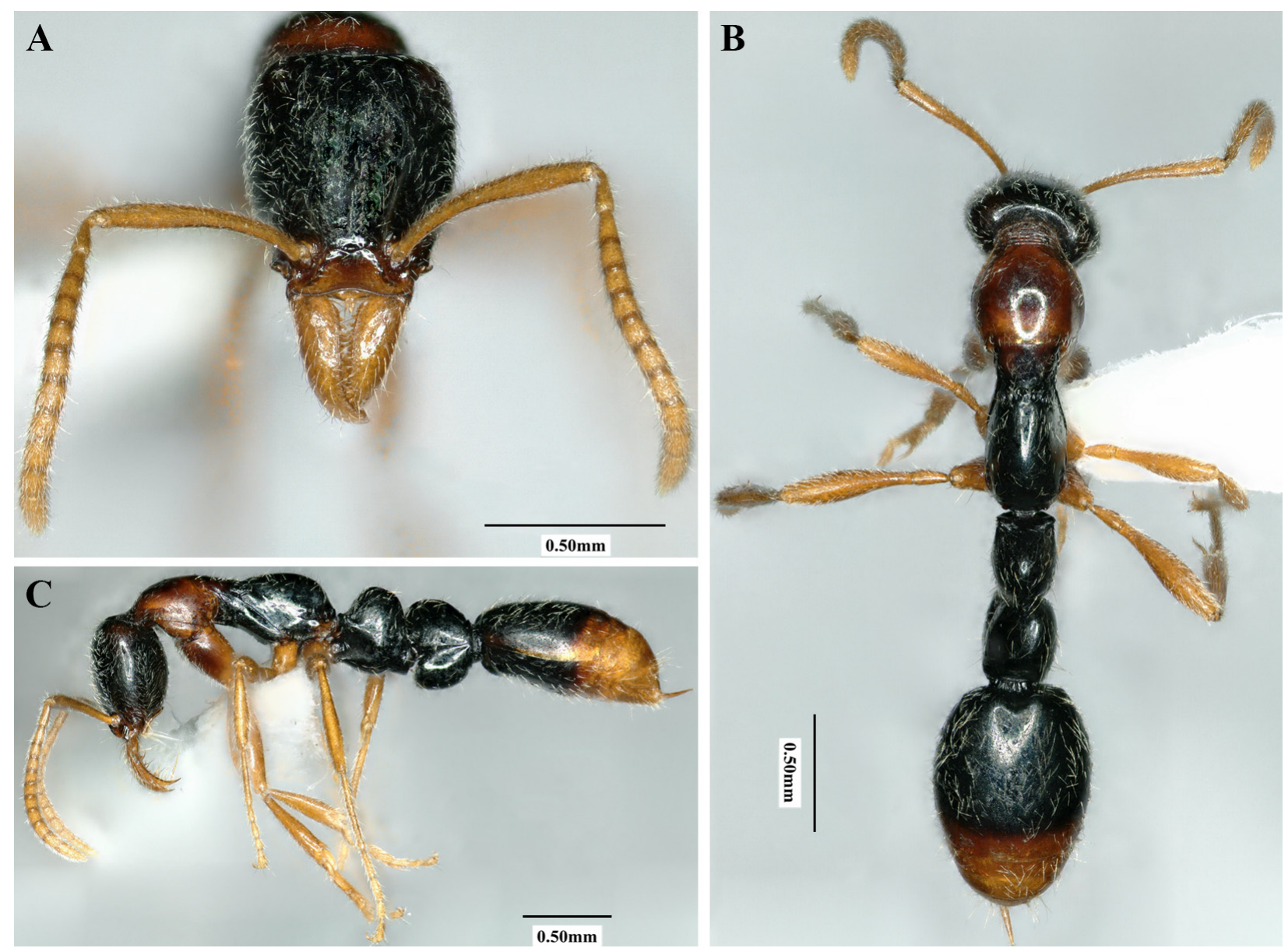

Figure 2. Worker of Protanilla gengma from India. A. Head, full-face view. B. Dorsal view. C. Profile view. 

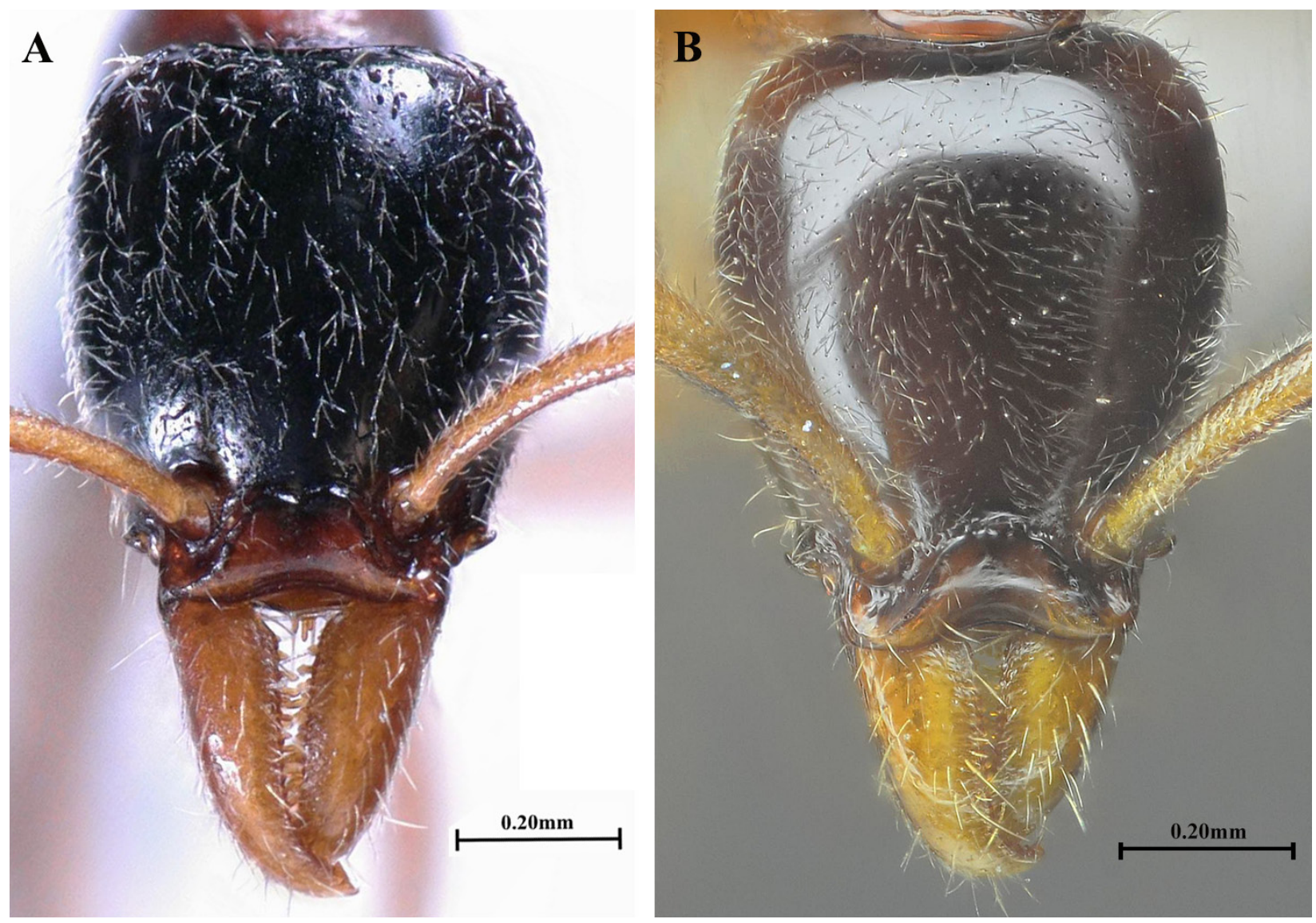

Figure 3. Comparison between Protanilla gengma worker from India and the holotype: head (full-face view). A. Specimen from Mizoram, India. B. Holotype specimen from Yunnan Province, China.

\section{Discussion}

Protanilla is a rarely collected ant genus, with most species reported only once or only from the type locality (Brandão et al. 2008; AntWiki 2020). Protanilla rafflesi is the most widely distributed species within the genus, found in Borneo, Indonesia, Malaysia, and Singapore, and followed by $P$. lini, which has been reported from Japan and Taiwan. Protanilla gengma was previously known only from the Yunnan Province, China, and our study extends its occurrence to the Indian subcontinent. All other Protanilla species are so far known only based on their type locality. The descriptions of several new species since the genus was erected highlights the potential for additional future discoveries of species in this genus. Previous studies on leptanillines also suggest the importance of using non-conventional extraction methods for sampling ants belonging to this subfamily (Wong and Guénard 2017; Man et al. 2017).

The reports of $P$. wardi by Bharti and Akbar (2015) and of P. flamma by Baidya and Bagchi (2020) from the Western Ghats have been the only times that this genus has been recorded from India. While more than 400 species of ants have been reported from Northeast India (Bharti et al. 2016), it is surprising no species of leptanilline ants have been collected from this region until now. Therefore, our report is an important contribution to the understanding of the Indian myrmecofauna and highlights the need for additional sampling in the Eastern Himalayas.

\section{Acknowledgements}

We thank Mr John R. Vanlalfela for assistance during fieldwork in Mizoram. We also offer our sincere gratitude to the forest officials from the Department of Environment, Forests and Climate Change, Government of Mizoram. We are grateful to the Department of Biotechnology, Government of India for the financial assistance through a major research project on "Bio-resources and Sustainable livelihood in North East India (BT/01/17/ NE/TAX). We would like to thank Prof. Dr Zhenghui Xu (Faculty of Conservation Biology, Southwest Forestry College, Yunnan Province, China) for providing images of the holotype of $P$. gengma and Sneha Haridas (ATREE, Bengaluru) for helping us in preparing the distribution map. Sincere gratitude is given to Dr Seena Narayanan Karimbumkara, Dr Aniruddha Marathe, Harsha Malhotra, and Geetha K Wilson (ATREE, Bengaluru) for their valuable suggestions. We are also grateful to all the reviewers for their valuable comments and suggestions.

\section{Authors' Contributions}

This project was conceived by DRP. Field collection and specimen curation protocol were designed and carried 
out by PA and KA. PA and KA wrote the manuscript, and the project was supervised by DRP.

\section{References}

AntCat (2020) An online catalog of the ants of the world. Leptanillinae Emery, 1910. https://www.antcat.org/catalog/430164. Accessed on: 2020-10-09.

AntWeb (2020) AntWeb. Version 8.45.1. Species: Protanilla bicolor $\mathrm{Xu}, 2002$. California Academy of Sciences. https://www.antweb. org/images.do? species $=$ bicolor $\&$ genus $=$ protanilla $\&$ rank $=\mathrm{spec}$ ies. Accessed on: 2020-07-09.

AntWiki (2020) AntWiki-the ants online. Protanilla. https://www. antwiki.org/wiki/Protanilla. Accessed on: 2020-07-09.

Aswaj P, Anoop K, Priyadarsanan DR (2020) First_record_protanilla_gengma_indian_subcontinent. Check List. Occurrence dataset. https://doi.org/10.15468/8mut7m. Accessed via GBIF.org on: 2020-11-14.

Baidya P, Bagchi S (2020) A new species of Protanilla Taylor 1990 (Hymenoptera: Formicidae: Leptanillinae) from India. Halteres 11: 19-24. https://doi.org/10.5281/zenodo.3941686

Baroni-Urbani C (1977) Materiali per una revisione della sottofamiglia Leptanillinae Emery (Hymenoptera: Formicidae). Entomologica Basiliensia 2: 427-488.

Baroni-Urbani C, De Andrade ML (2006) A new Protanilla Taylor, 1990 from Sri Lanka. Myrmecologische Nachrichten 8: 45-47.

Bharti H, Akbar SA (2015) First record of genus Protanilla (Hymenoptera: Formicidae: Leptanillinae) from India with description of a new species. Journal of Asia Pacific Entomology 18 (3): 573 576. https://doi.org/10.1016/J.ASPEN.2015.04.008

Bharti H, Guénard B, Bharti M, Economo EP (2016) An updated checklist of the ants of India with their specific distributions in Indian states (Hymenoptera, Formicidae). ZooKeys 551: 1-83. https://doi.org/10.3897/zookeys.551.6767

Bolton B (1987) A review of the Solenopsis genus-group and revision of Afrotropical Monomorium Mayr (Hymenoptera: Formicidae). Bulletin of the British Museum (Natural History) Entomology 54 (3): $263-452$

Bolton B (1990) The higher classification of the ant subfamily Leptanillinae (Hymenoptera: Formicidae). Systematic Entomology 15 (3): 267-282. http://doi.org/10.1111/j.1365-3113.1990.tb00063.x

Borowiec ML, Rabeling C, Brady SG, Fisher BL, Schultz TR, Ward PS (2019) Compositional heterogeneity and outgroup choice influence the internal phylogeny of the ants. Molecular Phylogenetics and Evolution 134: 111-121. https://doi.org/10.1016/j. ympev.2019.01.024

Brandão CRF, Feitosa RM, Schmidt FA, Solar RRDC (2008) Rediscovery of the putatively extinct ant species Simopelta minima (Brandão) (Hymenoptera, Formicidae), with a discussion on rarity and conservation status of ant species. Revista Brasileira de
Entomologia 52 (3): 480-483.

Dias RKS, Yamane S, Akbar SA, Pieris HAWS, Wachkoo AA (2019) Discovery of the worker caste of Protanilla schoedli Baroni Urbani \& De Andrade (Formicidae: Leptanillinae) in Sri Lanka. Oriental Insects 53 (2): 160-166. https://doi.org/10.1080/003053 16.2018.1476273

Guénard B, Weiser MD, Gomez K, Narula N, Economo EP (2017) The Global Ant Biodiversity Informatics (GABI) database: synthesizing data on the geographic distribution of ant species (Hymenoptera:Formicidae).Myrmecological News 24:83-89.https://doi.org/ 10.25849/myrmecol.news_024:083

Hsu PW, Hsu FC, Hsiao Y, Lin CC (2017) Taxonomic notes on the genus Protanilla (Hymenoptera: Formicidae: Leptanillinae) from Taiwan. Zootaxa 4268 (1): 117-130. https://doi.org/10.11646/zoo taxa.4268.1.7

Janicki J, Narula N, Ziegler M, Guénard B, Economo EP (2016) Visualizing and interacting with large-volume biodiversity data using client-server web-mapping applications: the design and implementation of antmaps.org. Ecological Informatics 32:185-193. https://doi.org/10.1016/j.ecoinf.2016.02.006

Man P, Ran H, Chen Z, Xu Z (2017) The northern-most record of Leptanillinae in China with description of Protanilla beijingensis sp. nov. (Hymenoptera: Formicidae). Asian Myrmecology 9: 1-12. https://doi.org/10.20362/am.009008

QGIS Development Team (2020) QGIS Geographic Information System (version 3.10.4). Open Source Geospatial Foundation Project. http://qgis.osgeo.org. Accessed on: 2020-6-15.

Terayama M (2009) A synopsis of the family Formicidae of Taiwan (Insecta, Hymenoptera). Research Bulletin of Kanto Gakuen University. Liberal Arts 17: 81-266.

Terayama M (2013) Additions to knowledge of the ant fauna of Japan (Hymenoptera; Formicidae). Memoirs of the Myrmecological Society of Japan 3: 1-24.

Ward PS (2014) The phylogeny and evolution of ants. Annual Review of Ecology, Evolution and Systematics 45: 23-43. https://doi.org/10. 1146/annurev-ecolsys-120213-091824

Wong MKL, Guénard B (2017) Subterranean ants: summary and perspectives on field sampling methods, with notes on diversity and ecology (Hymenoptera: Formicidae). Myrmecological News 25: 1-16. https://doi.org/10.25849/myrmecol.news_025:001

$\mathrm{Xu}$ ZH (2002) A systematic study on the ant subfamily Leptanillinae of China. Acta Entomologica Sinica 45: 115-120.

Xu ZH (2012) Furcotanilla, a new genus of the ant subfamily Leptanillinae from China with descriptions of two new species of Protanilla and P. rafflesi Taylor (Hymenoptera: Formicidae). Sociobiology 59 (2): 477-491. https://doi.org/10.13102/sociobiology.v59 i2.612

Xu ZH, Zhang JL (2002) Two new species of the ant subfamily Leptanillinae from Yunnan, China (Hymenoptera: Formicidae). Acta Entomologica Sinica 27: 139-144. 